\section{Festas, Trabalho e Religião: o Engenho dos Andrade em Santo Antonio de Lisboa, Florianópolis, Santa Catarina}

Festivals, work and religion: Engenho dos Andrade in Santo Antonio de Lisboa, Florianópolis, Santa Catarina

\section{Resumo}

A história do Distrito de Santo Antônio de Lisboa - formado pelas localidades de Sambaqui, Barra do Sambaqui, Cacupé e Santo Antonio de Lisboa - prende-se às políticas da metrópole portuguesa em relação às terras da América do Sul. Em 1750, D. João V, rei de Portugal, elevou à categoria de Freguesia o povoado de Nossa Senhora das Necessidades da Praia Comprida. Este capítulo tem por objetivo destacar o cotidiano do engenho de farinha de mandioca do conjunto Casarão e Engenho dos Andrade que sobrevive aos dias atuais na Ilha de Santa Catarina, apesar da urbanização e da falta de políticas públicas de preservação do patrimônio.

Palavras-chave: Festa, Trabalho, Religião, Patrimônio, Engenho dos Andrade.

\section{Abstract}

History related to Santo Antônio de Lisboa District - formed by Sambaqui, Barra do Sambaqui, Cacupé and Santo Antonio de Lisboa localities - is connected to Portuguese metropolis policies in relation to the lands of South America. In 1750, D. João V, king of Portugal, raised to the category of Parish the village of Nossa Senhora das Necessidades da Praia Comprida. The objective of this chapter is to highlight the daily life of the cassava flour mill at Casarão and
Prof. $^{a}$ Dr. ${ }^{a}$. Arlete Assumpção Monteiro.

Possui Doutorado em História Econômica pela Universidade de São Paulo (USP); Pós-Doutorado em Estudos sobre a América Latina pela Universidade Pablo de Olavide, Sevilha, Espanha;

Pós-Doutorado pelo Instituto de Iberoamérica da Universidade de Salamanca, Espanha. Professora titular do Programa de Educação da Pontifícia Universidade Católica de São Paulo (PUC-SP); membro do Instituto Histórico e Geográfico de Santa Catarina.

E-mail: arlete.as@gmail.com 
Engenho dos Andrade complex, which survive to the present day in Santa Catarina Island, despite urbanization and the lack of public policies for the preservation of the patrimony.

Keywords: Party, Work, Religion, Heritage, Engenho dos Andrade.

\section{Introdução}

Poucos engenhos de farinha de mandioca sobraram na Ilha de Santa Catarina, entre os quais destaca-se o conjunto Casarão e Engenho dos Andrade, em Santo Antonio de Lisboa, Florianópolis, SC, persistindo ao tempo, à urbanização e falta de políticas públicas de preservação do patrimônio arquitetônico e cultural. Localizado próximo ao mar, o engenho tem sua história relacionada ao abastecimento das embarcações que ancoravam no povoado, em busca de água e gêneros alimentícios para prosseguimento da viagem.

Cabe destacar que desde a Descoberta do Brasil (1500), a Ilha de Santa Catarina ficou conhecida entre os navegadores como porto para reabastecimento das naus.

Descoberto o Brasil em 1500, a Ilha não demorou muito a assumir a condição de porto estratégico na rota das expedições dos exploradores daquele século dos descobrimentos, pela sua localização privilegiada Porto, na concepção dos navegadores da época, era um acidente hidrográfico que permitisse as frotas adentrarem e fundearem de forma segura... Assim, as baías Sul e Norte da Ilha eram perfeitas como abrigo natural das embarcações dos pioneiros do Atlântico Sul, permitindo o abastecimento de água e lenha, suprimento de víveres e realização de reparos no madeirame das naus, eventualmente avariado. Chamava-se aguada e refresco essa parada.. (MOSIMANN, 2010, p. 12-13).

A história do Distrito de Santo Antonio de Lisboa - formado pelas localidades de Sambaqui, Barra do Sambaqui, Cacupé e Santo Antonio de Lisboa - prende-se às políticas da metrópole portuguesa em relação às terras da América do Sul. Em 1750, D. João V, rei de Portugal, elevou à categoria de Freguesia o povoado de Nossa Senhora das Necessidades da Praia Comprida, local onde se instalou o sargento-mor Manoel Manso de Avelar - considerado o segundo povoador da Ilha de Santa Catarina - com um entreposto em Sambaqui, para funcionar como comércio marítimo com os navegadores de diferentes procedências que aportavam no local. A igreja de Nossa Senhora das Necessidades (Figura 1) foi construída em terreno doado por Dona Clara Manso de Avelar, filha de Manoel Manso de Avelar.

Figura 1 - Igreja de Nossa Senhora das Necessidades. Santo Antonio de Lisboa, Florianópolis, SC.

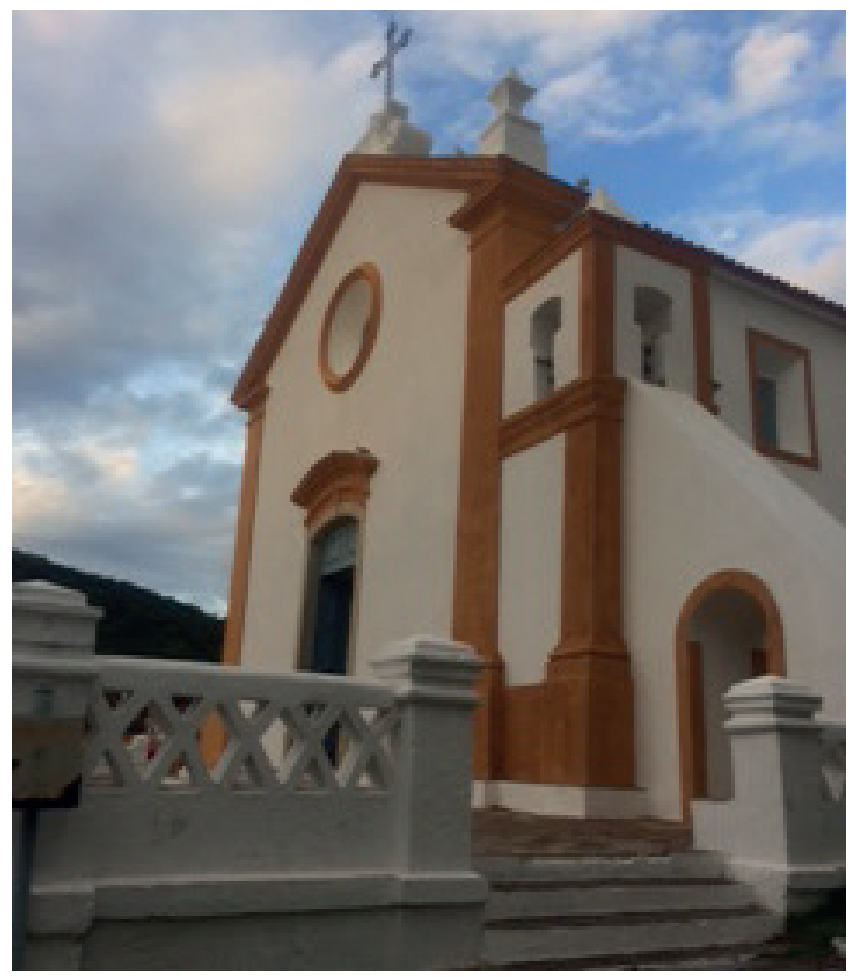

Fonte: acervo da autora

Conforme assinala João Carlos Mosimann, no livro Catarinenses. Gênese e história (2010, p. 124), entre os pioneiros da Ilha, em 1715, encontrava-se Manoel Manso de Avelar:

Manoel Manso de Avelar, nascido em Lisboa, em 1662, segundo se presume chegou ao Brasil com pouca idade, conforme declarava. Estava entre os destacados 
habitantes da Ilha, e certamente os liderava [...] teve duas filhas Isabel Rodrigues... e Clara Manso de Avelar, casada com o galego Francisco Antonio Branco e moradora na enseada de Santo Antônio.

O comércio dos moradores com os navegadores que ancoravam na Ilha era contrário às determinações superiores, todavia, assumia importante papel econômico para seus habitantes. "A frente desse comércio estava Manso de Avelar com um entreposto na praia da Aguada, em Sambaqui, de onde os navios também eram abastecidos de água" (MOSIMANN, 2010, p. 124). Segundo aponta o pesquisador e professor Sérgio Ferreira ([20--b]), Manso de Avelar liderava a população existente no povoado, preferindo manter um bom relacionamento com os navegadores que aportavam na itha $e$ não ter o fim de Dias Velho, morto por piratas.

Manoel Manso de Avelar não quis repetir o fim trágico de Francisco Dias Velho, fundador de Desterro morto por piratas. Relacionava-se muito bem com os navios estrangeiros que aportavam na Ilha. Quando Amedée François Frézier passou pela Ilha, em 1712, escreveu que Manoel Manso de Avelar governava uma população de 147 brancos. Com toda a Ilha de Santa Catarina à disposição para a sua moradia, ele escolheu Sambaqui por causa das águas que tinha e fixou morada bem junto ao córrego que abastecia de água os navios que por ali passavam (FERREIRA, [20--b]).

Com a criação do entreposto de Manoel Manso, o povoado cresceu e continuou sendo visitado por embarcações estrangeiras, que negociavam com a população, mesmo a contragosto das autoridades.

Em 23 de junho de 1719, ancorava nas águas da Baía Norte o Speedwell, um navio de guerra inglês capitaneado por George Shelvocke, de apenas 28 anos, com cem homens a bordo. Shelvocke saíra da Inglaterra com a missão de pilhar navios espanhóis e transformara-se em um verdadeiro corsário, cumprindo a proeza de dar volta ao mundo, depois de enfrentar dois motins, um dos quais na Ilha de Santa Catarina (MOSIMANN, 2010, p. 126).

Pode-se assinalar que os moradores do povoado de Nossa Senhora das Necessidades - Santo Antonio de Lisboa, objeto do presente estudo - já fabricavam farinha de mandioca para prover os navegadores e sua tripulação que ali ancoravam.

Finalmente em 8 de agosto de 1719, o Speedwell despedia-se da Ilha, levando um estoque de provisões compradas dos moradores, demonstração de que sua escassa população era economicamente ativa: 200 grandes peixes salgados, 150 alqueires de farinha de pau (mandioca), tão fina quanto a nossa farinha de aveia, 160 alqueires de trigo-turco (milho) e um bom estoque de fumo. Parte das mercadorias foi trocada por sal, do qual os habitantes da Ilha tinham carência. [...] Além das provisões, compraram 21 cabeças de gado (MOSIMANN, 2010, p. 126).

A Ilha continuava recebendo embarcações. Em 21 de dezembro de 1740, a esquadra inglesa comandada por George Anson, composta de cinco naus de guerra e três navios, com 1.680 homens a bordo, dos quais trezentos doentes, desembarcados e alojados em tendas de guerra, tinha a missão de rumar ao Pacífico para hostilizar o tráfego marítimo das colônias espanholas. "Levantaram ferros" em 18 de janeiro de 1741, com a impressão registrada pelo comandante da esquadra inglesa: "Desinfetados, abastecidos e reparados os navios, levantaram ferros [...] com a impressão registrada por Anson, de que se tratava do melhor lugar de refresco para os armadores ingleses, o porto mais considerável de toda a América meridional" (MOSIMANN, 2010, p. 135).

O povoado de Nossa Senhora das Necessidades foi elevado à categoria de Freguesia por meio da Provisão de 27 de abril de 1750, segundo determinação da Coroa portuguesa. A igreja de Nossa Senhora das Necessidades foi elevada à 
condição de matriz em 1755. A localidade continuou conhecida pelos moradores como Santo Antonio, devido à devoção ao Santo pela doadora do terreno para a construção da igreja: Dona Clara de Avelar. O nome da localidade Santo Antonio de Lisboa somente foi oficializado em 1948.

\section{A chegada dos açorianos}

A Provisão Régia de 9 de agosto de 1747 fixou as normativas do Edital que seria publicado nas Ilhas dos Acores para a vinda de quatro mil casais com destino às terras brasileiras, que seriam acolhidos em Santa Catarina, desde o rio São Francisco do Sul até o Serro de São Miguel, no sertão de Santa Catarina. Nessa ocasião, a Coroa portuguesa tinha grande preocupação com o perigo espanhol na fronteira Sul, uma vez que a Capitania de Santa Catarina fazia fronteira com a Província do Rio da Prata.

Segundo o historiador Walter Piazza (apud MOSIMANN, 2010, p. 145), a listaram-se 1.294 casais e 1.039 solteiros, totalizando 7.817 pessoas. Procedentes dos Açores e da Ilha da Madeira, desembarcaram efetivamente 5.943 pessoas, no período de outubro de 1747 a abril de 1756. Para acolher os colonos foram criados núcleos de assentamento. Os últimos açorianos a desembarcar foram instalados na freguesia de Nossa Senhora das Necessidades, de Santo Antonio - objeto da presente pesquisa - à época, oficialmente povoada há meio século.

Por volta de 1777, a população da Itha de Santa Catarina era formada por açorianos em sua maioria e descendentes de vicentinos e paulistas, povoadores da Ilha desde os primórdios de 1700. A base econômica era a farinha de mandioca; a carne seca era importada do Rio Grande. A única atividade econômica de destaque provinha do mar: a pesca da baleia para a produção de óleo - destinado a outros locais.' Duas freguesias da Ilha se destacavam: Nossa Senhora das Necessidades - conhecida como Santo Antonio - e Nossa Senhora da Conceição, na Lagoa.

A iluminação do Rio de Janeiro, à época de D. João VI e do Império, era mantida com óleo de baleia.
O porto de Nossa Senhora das Necessidades se comunicava semanalmente com o Rio Grande - do Sul -, despachando víveres alimentícios e outras mercadorias como pólvora e cal. Farinha de mandioca, além da produção local, era recebida em toneladas de outras freguesias e vilas como São Francisco, Cananeia e Paranaguá. Nas mesmas embarcações - sumacas - seguiam correspondências locais ou da Colônia e notícias tanto do Rio de Janeiro como da Corte. O porto servia igualmente ao transbordo de tropas, armamento, munições e fardamento (MOSIMANN, 2010, p. 171).

A invasão da Ilha de Santa Catarina pelos espanhóis ocorreu na madrugada de 24 de fevereiro de 1777, os quais chegaram pelo Norte da Ilha, onde se localiza a Fortaleza de São José da Ponta Grossa, comunidade e praia de Jurerê. O sistema defensivo português não funcionou. A ideia de construir fortalezas era justamente para evitar ataques estrangeiros à possessão portuguesa. "Os espanhóis vieram para a Ilha de Santa Catarina preparados para ficar. Tanto que as tropas trouxeram sacerdotes, que se espalharam pelas freguesias - um claro sinal da pretensão de longa ocupação [...]" (DAMIÃO, 2017).

A notícia rapidamente se propagou. A população da Ilha foi acometida de pânico e terror com a presença do temido Cevallos, que era, para os portugueses, o que tinha sido El Cid aos mouros e cuja aproximação fugiam desesperados (MOSIMANN, 2010, p. 178).

Os moradores da Ilha, passado o terror inicial, retornaram às suas moradias e passaram a conviver com o inimigo. As "burras" do rei, ou seja, as arcas que continham moedas foram apreendidas pelos espanhóis. Os religiosos portugueses foram substituídos. Chegaram 101 embarcações para a ocupação da Ilha, 84 continuaram viagem. 523 praças que mantinham as fortalezas e a segurança da Ilha foram considerados prisioneiros e levados ao interior do território argentino. As negociações foram realizadas entre os dois países: Portugal e Espanha, que culminou com o Tratado de Santo Ildefonso, que restituía o território aos portugueses; em 2 de agosto de 1778, o último 
contingente de espanhóis se retirava da Ilha. Alguns, porém, desertaram do grupo invasor e permaneceram no local, fincando raízes, registrando os seus atos de deserção.

Um registro precioso sobre a Ilha de Santa Catarina foi realizado pela expedição russa chefiada por Krusenstern, que trazia vários cientistas alemães e o Barão de Langdorff, em 1803. A expedição foi patrocinada pelo Czar Alexander I e era composta por duas embarcações (CAROLA, 2010, p. 550).

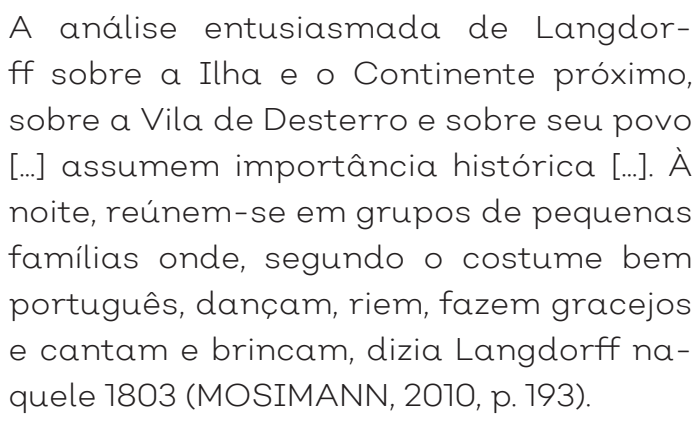

Otrabalho na Freguesia de Nossa Senhora das Necessidades e a participação das mulheres em diferentes atividades, inclusive junto às embarcações que ancoravam no porto da povoação, é registrado pelo historiador Sergio Luiz Ferreira ([20--b]), no artigo Santo Antonio entre as águas.

Esse contato com navios estrangeiros em demanda de água doce possibilitou um rico comércio dos moradores com tais tripulações. Até meados de 1960 era comum as pessoas de Sambaqui "negociarem a bordo". Na realidade, tratava-se de escambo: trocava-se farinha de mandioca, beiju, feijão, milho, amendoim, frutas, passarinhos e rendas de bilro por fazendas - tecidos -, sal e querosene. Manoel Manso de Avelar foi o décimo-segundo avô da autora deste estudo, de modo que essa tradição permaneceu na família até o pai da autora, quem ainda negociou a bordo. A avó, Emília Homem Ferreira - Dona Milóca -, quando casou, em 1941, com Timóteo Antônio Ferreira, foi morar em Sambaqui. Assim, enquanto Timóteo trabalhava nos barcos de pesca no Rio Grande, Dona
Milóca ia negociar a bordo dos navios que ficavam ancorados entre as ilhas de Anhatomirim e Ratones. Comumente surpreendida pelo vento Sul, precisava ficar arribada no forte de Santo Antônio da Ilha de Ratones, enquanto os filhos pequenos esperavam em casa pela mãe, às vezes, por até três dias!

Recentemente, em entrevista obtida junto às rendeiras de Sambaqui, a autora do presente capítulo escutou, entre histórias de bruxa e lobisomem, o seguinte relato: "Eu era criança, minha mãe ia remando a canoa até as embarcações [navios] que ancoravam aí na frente, para vender rendas de bilros" (Trabalho de campo, fev. 2018).

Cabe destacar que a importância da pesca em Santo Antonio de Lisboa, principalmente a pesca de espinhel, assegurava a subsistência das famílias. As mulheres de Santo Antonio de Lisboa sabem fazer rendas de bilros, uma tradição mantida através das gerações. Enquanto tecem os fios, contam histórias dos antepassados: "As mulheres faziam renda esperando seus maridos retornarem da pesca; o fogão à lenha ficava acesso para, quando os homens chegassem, o peixe ser assado na hora" (Trabalho de campo, fev. 2018).

No antigo posto da Alfândega fica a Associação do Bairro de Sambaqui, local onde as rendeiras se reúnem e tecem fios na arte de trabalhar com bilros. Das quintas-feiras aos domingos, das 17 às 19h, o casarão é aberto ao público para visitação. Nesse local também estão os bonecos que fazem parte do folclore Boi-de-Mamão, tradicional apresentação na comunidade, onde as rendeiras cantam nas apresentações e dançam o Pau-de-Fita.

\section{Engenho dos Andrade em Santo Antonio de Lisboa}

O complexo Casarão e Engenho (Figura 2) foi erigido por Agenor José de Andrade. $\mathrm{Na}$ fachada da casa figura a data da sua construção: 1860. 
Figura 2 - Engenho dos Andrade, onde é realizada a Farinhada do Divino. Santo

Antonio de Lisboa, Florianópolis, SC.

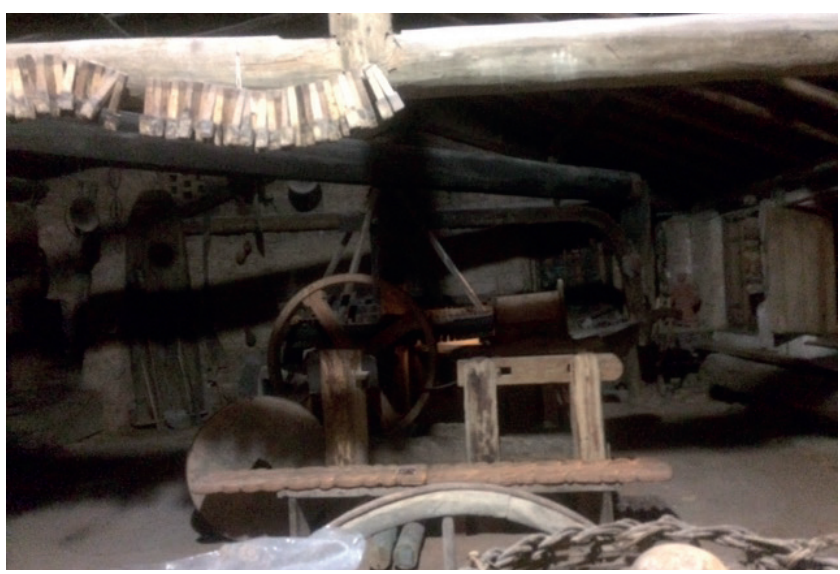

Fonte: acervo da autora (fev. 2018).

Agenor de Andrade formou a sua família e criou quatorze filhos, cujos descendentes lutam para manter o patrimônio - Casarão e Engenho -, uma vez que o desenvolvimento turístico da região trouxe maior número de veículos que trafegam na única via de acesso ao centro da vila, abalando a antiga estrutura de madeira, conforme relatou um informante durante o estudo realizado na região.

Logo na entrada do Engenho estão os personagens do folclore da Ilha, entre os quais o Boi-de-Mamão (Figura 3). Em visita ao complexo, em fevereiro de 2018, presenciou-se a preocupação com o patrimônio arquitetônico por parte dos atuais proprietários, descendentes de Agenor de Andrade.

Figura 3 - Engenho dos Andrade. Preservação da cultura da Ilha de Santa Catarina: personagens do Boi-de-Mamão.

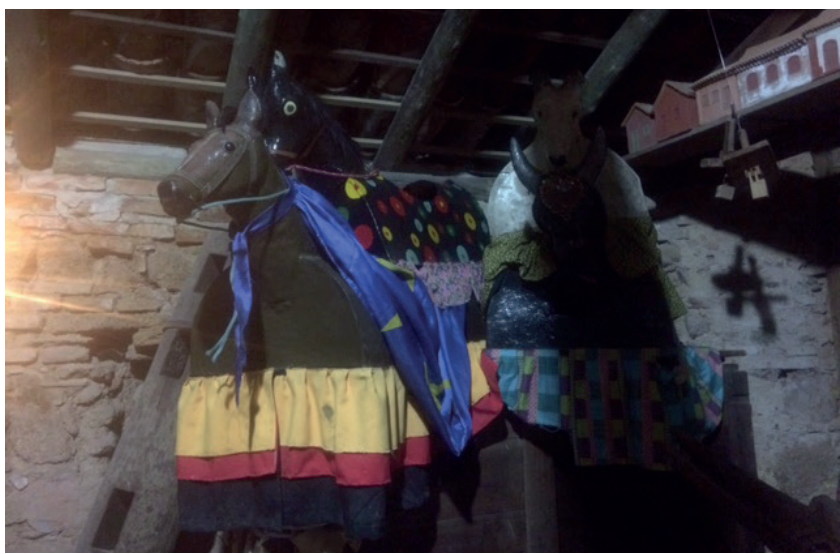

Fonte: acervo da autora (fev. 2018).
O conjunto é composto pelo engenho geminado lateralmente à antiga moradia, podendo-se considerar que foi construído na época da formação da Freguesia de Santo Antonio de Lisboa, fase de grande produção de gêneros alimentícios - tais como café e farinha de mandioca - para abastecimento local e das embarcações que ancoravam no porto da Freguesia em busca de água e comida.

O aparecimento de rachaduras no $\mathrm{Ca}$ sarão e Engenho dos Andrade, imóvel tombado em 1860, causa preocupação à família, que denunciou a situação ao Ministério Público. De acordo com o proprietário, Claudio de Andrade, desde que foram realizadas obras da rede de esgoto no Caminho dos Açores, onde está localizado o Casarão, o asfalto ficou cheio de recortes e buracos, as tampas das caixas de inspeção da Companhia Catarinense de Águas e Saneamento (Casan) estão soltas e desniveladas, de modo que toda vez que ônibus e veículos pesados trafegam por essa rua, provocam trepidações. "[...] de uns cinco meses para cá este problema começou. Um amigo arquiteto me avisou que as rachaduras são os primeiros sinais de problemas, ainda mais como é uma casa antiga. As paredes foram feitas de óleo de baleia e o terreno de toda região era mangue [...]" (WOLFF, 2017).

O Engenho dos Andrade tem papel importante na Festa do Divino e de Nossa Senhora das Necessidades, em Santo Antonio de Lisboa, pois abre tal evento com a Farinhada do Divino (Figura 2), uma tradição mantida nessa comunidade. Em 2018, começou ao final de agosto, estendendo-se pelo mês de setembro.
A tradicional Farinhada marca o início oficial da Festa do Divino de Santo Anto- nio de Lisboa, nos dias 1 e 2 de setembro, no Casarão Engenho dos Andrade. Em sua $21^{a}$ edição terá a novena rezada em latim, shows musicais e gastronomia típi- ca do Engenho. Entrada é franca, venha participar (CALENDÁRIO FLORIPA, 2018).

A farinha de mandioca produzida no Engenho dos Andrade foi descrita por um dos membros 
da família à autora do presente capítulo da seguinte forma: "Nós plantamos a mandioca, lá no morro. Cuidamos da plantação até a época da colheita. Trazemos a mandioca aqui no Engenho. No dia de se fazer a farinha a comunidade participa" (Trabalho de campo, fev. 2018).

A Festa do Divino Espírito Santo é a principal confraternização da comunidade, ligada às tradições da religiosidade açoriana, em Santo Antonio de Lisboa. A construção de engenhos na Ilha de Santa Catarina destinava-se à fabricação de farinha de mandioca, mas também de açúcar, melado e cachaça (CAMPOS, 1991).

D. Pedro II visitou Santa Catarina em outubro de 1845, quando Santo Antonio de Lisboa recebeu a primeira rua calçada do Estado de Santa Catarina, construída para que o imperador pudesse caminhar, quando de sua chegada à freguesia.

Ademais, Santo Antonio de Lisboa é uma das atrações turísticas de Florianópolis, SC, com muitos restaurantes, bares, cafés e lojas de artigos locais; o maior afluxo de pessoas ocorre na hora do pôr do Sol (Figura 4).

Figura 4 - Pôr do Sol. Centro do Distrito de Santo Antonio de Lisboa, Florianópolis, SC (fev. 2018).

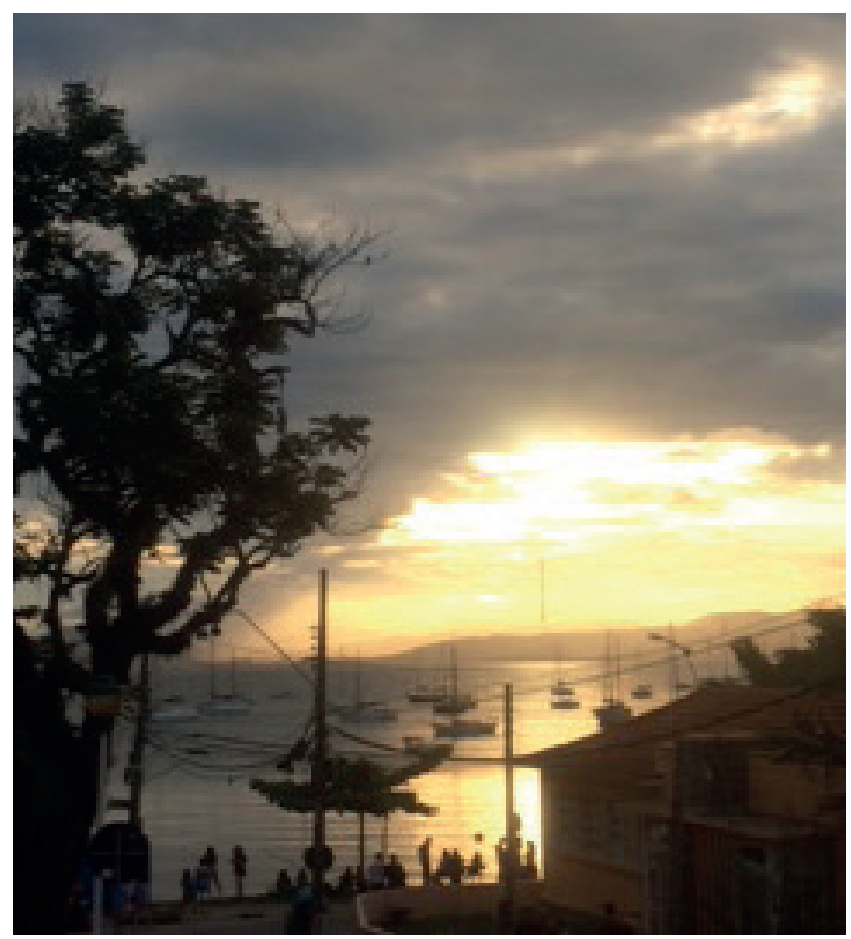

Fonte: acervo da autora.
Santo Antonio de Lisboa tem causos de bruxas que amedrontam as crianças, de fantasmas e das façanhas dos pescadores nos mares do Sul. Muita história para ser registrada nas falas das mulheres que tecem fios, manuseando os bilros com cadência e cantigas. Conta-se sobre o trabalho nos engenhos, os viajantes e, atualmente, os turistas que visitam a antiga freguesia, advindos de várias partes do mundo.

\section{Considerações Finais}

O século XIX foi o período da prosperidade econômica de Nossa Senhora das Necessidades, com grande produção de farinha de mandioca, café e cana-de-açúcar, onde o porto servia para o escoamento da produção agrícola da comunidade e dos povoados do Norte da Ilha. A freguesia possuía casas comerciais, algumas mantidas até a atualidade.

Na década de 1920, iniciou-se o período de decadência da freguesia de Nossa Senhora das Necessidades, de modo que muitos moradores se mudaram para o Centro de Florianópolis, $\mathrm{SC}$, inclusive comerciantes.

Todavia, com a construção da estrada SC 401, que liga o centro de Florianópolis ao Norte da Ilha, Santo Antonio de Lisboa ressurgiu para mostrar as histórias dos casarões, das pedras por onde passou o imperador e a sua comitiva, dos barcos e da criação de ostras, um dos atrativos gastronômicos da antiga freguesia de Nossa Senhora das Necessidades e da Farinhada do Divino, local em que o Casarão dos Andrade é o cenário principal.

\section{Referências}

\section{CALENDÁRIO Floripa. [Florianópolis, SC], 2018.}

CAROLA, C. R. Natureza admirada, natureza devastada: história e historiografia da colonização de Santa Catarina. Varia História, Belo Horizonte, MG, v. 26, n. 44, p. 547-572, jul./dez. 2010. Disponivel em: <http://www.scielo.br/pdf/vh/v26n44/a77v2644. pdf>. Acesso em: 15 out. 2018. 
DAMIÃO, C. A Ilha de Santa Catarina sob o domínio da Espanha. 26 fev. 2017. Disponível em: <https:// ndonline.com.br/florianopolis/coluna/carlos-damiao/a-ilha-de-santa-catarina-sob-dominio-da-espanha-ha-240-anos>. Acesso em: 15 out. 2018.

FERREIRA, S. L. Um pouco de história. Santo Antonio de Lisboa. [20--a]. Disponível em: <http://cartoriosilva.com.br/santo_antonio_lisboa.html>. Acesso em: 15 out. 2018.

Santo Antonio entre águas. [20--b]. Disponivel em: <http://www.baiacudealguem.com.br>. Acesso em: 15 out. 2018.

Histórias quase todas verdadeiras: 300 anos de Santo Antonio e Sambaqui. Florianópolis, SC: Editora das Águas, 1998.

JESUS, G. V. de. A pequena produção mercantil: da ascensão à decadência em Santo Antonio de Lisboa e Sambaqui (Florianópolis, SC). [20--].
Disponível em: <http://observatoriogeograficoamericalatina.org>. Acesso em: 15 out. 2018

MARTINELLO, D. M. Santo Antonio de Lisboa: o pescado tecendo a sua própria rede. 1992. Dissertação (Mestrado em Educação) - Centro de Ciências da Educação da Universidade Federal de Santa Catarina, Florianópolis, SC, 1992.

MOSIMANN, J. C. Catarinenses. Gênese e história. Florianópolis, SC: Edição do Autor, 2010.

PIAZZA, W. F. A colonização de Santa Catarina. Florianópolis, SC: Palloti; BRDE, 1982.

SANTO Antonio de Lisboa. [20--]. Disponível em: <http://cartoriosilva.com.br/santo_antonio_lisboa. html>. Acesso em: 15 out. 2018.

WOLFF, G. A hora de Santa Catarina. 2017. Disponivel em: <http://horadesantacatarina.clicrbs.com. $\mathrm{br} / \mathrm{sc} /$ geral/noticia/2017>. Acesso em: 15 out. 2018. 